\title{
La Guerra del Pacífico como referente nacional y punto condicionante de las relaciones chileno-peruanas*
}

\section{The War of the Pacific as a national reference point and determinant issue of Chilean-Peruvian Relations}

\author{
Emilio José Ugarte Díaz ${ }^{* *}$ \\ Universidad Mayor, Santiago, Chile
}

Recibido: 5 de noviembre de 2012. Aprobado: 19 de agosto de 2014 .

\begin{abstract}
Resumen
El presente artículo analiza las consecuencias que causó la Guerra del Pacífico (18791883) en la relación chileno-peruana. El conflicto ha condicionado las relaciones, siendo, incluso, utilizado como parte de la construcción identitaria y nacional de cada país. Se analizan las consecuencias que la guerra trajo para Perú, abordando las implicancias que tuvo en el desarrollo de la identidad nacional y sus relaciones con Chile. Posteriormente se realiza el mismo ejercicio en el caso chileno, examinando cómo el conflicto influyó en las percepciones e identidad del país y sus condicionantes en las relaciones con Perú. En las conclusiones se analiza en resumen el legado del conflicto y cómo este ha contribuido a distanciar ambas naciones en un camino lleno de resquemores.
\end{abstract}

Palabras clave: guerra, nación, relaciones bilaterales.

Este artículo es resultado de la tesis de Magíster en Estudios Internacionales, en el Instituto de Estudios Internacionales de la Universidad de Chile, 2011, titulada "Chile y Perú: cómo la idea de nación y los imaginarios condicionan la relación vecinal. 1883-1980".

** Magíster en Estudios Internacionales de la Universidad de Chile, licenciado en Historia de la misma universidad y periodista de la Universidad Alberto Hurtado. Actualmente hace clases en la Facultad de Educación de la Universidad Mayor. Correo electrónico: emiliougarted@gmail.com 


\begin{abstract}
This article analyzes the impact that the War of the Pacific (1879-1883) caused in the relationship between Chile and Peru. The conflict conditioned bilateral relations and has even been used as part of the national identity construction in both countries. First, we analyze the consequences that the war left in Peru by addressing the implications that the conflict had on the development of national identity and its relations with Chile. Later the same exercise is done in the case of Chile. In the conclusions of the article the legacy of the conflict in analyzed, as well as the way it has contributed to distancing the two nations on a path full of resentment and distrust.
\end{abstract}

Keywords: war, nation, bilateral relationship.

\title{
Introducción
}

La Guerra del Pacífico ${ }^{1}$ terminó en 1883 con la victoria de las fuerzas chilenas. El conflicto tuvo como principal consecuencia la anexión a perpetuidad de Tarapacá y Antofagasta por parte de Chile, que incluyó Tacna hasta 1929. Bolivia perdió su litoral y Perú debió soportar una ocupación militar por tres años. A partir de entonces las percepciones entre chilenos y peruanos se verían condicionadas, no solo por el conflicto bélico, sino por la situación creada por el intento de chilenización de Tacna y Arica, consolidándose la desconfianza y resquemor como elementos centrales de la relación; situación que permanece hasta hoy.

En Perú hay mucha desconfianza ante Chile y desde Chile hay desconfianza hacia Perú. En junio de 2010 aparecieron los resultados de una encuesta realizada en conjunto por el Instituto de Opinión Pública de la Pontificia Universidad Católica del Perú (IOP) y el Instituto de Ciencias Sociales de la Facultad de Ciencias Sociales e Historia de la Universidad Diego Portales (ICSO), que analizó las visiones que chilenos y peruanos tienen de sí mismos y del país vecino (Instituto de Opinión Pública, Pontificia Universi-

1 La Guerra del Pacífico fue un conflicto bélico que entre 1879 y 1883 enfrentó a Chile con el Perú y Bolivia a causa, en primera instancia, de los límites entre Chile y Bolivia; la existencia de un tratado secreto de alianza entre Bolivia y el Perú y los grandes depósitos salitreros de Antofagasta y Tarapacá. El conflicto terminó con la victoria chilena, que anexó los territorios en disputa, ocupó Lima y el Perú por tres años y mantuvo bajo su soberanía a Tacna y Arica hasta 1929. Bolivia perdió Antofagasta y su salida al mar, mientras Perú cedió Tarapacá y, hasta 1929, Tacna. 
dad Católica del Perú, Instituto de Ciencias Sociales de la Facultad de Ciencias Sociales e Historia de la Universidad Diego Portales, 2010).

La encuesta mostró, en primer lugar, que los chilenos tenían una alta confianza en su propio país. Un $42,3 \%$ de los encuestados sostuvo que Chile era un país importante en la región. Para los peruanos, Chile también es visto como uno de los países más importantes de la zona, solo superado por Brasil. Lo cual demuestra, para el investigador peruano Farid Kahhat, que Chile es un país de gran importancia para Perú. El académico del IOP argumentó, en el informe final, que la rivalidad histórica, el propio diferendo limítrofe, el mayor gasto en defensa de Chile y la asimetría en la interdependencia económica, favorable a nuestro país, es percibido por un sector de la sociedad peruana como un riego de seguridad.

Sin embargo, al mismo tiempo la encuesta consultó al público respecto a qué pensaba sobre al país vecino en el sentido de si acataría o no el fallo de la Corte Internacional de Justicia de La Haya sobre la demanda marítima del Perú. Mientras en Chile un 48,1\% de los consultados sostuvo que Perú acatará el dictamen de La Haya, un 60,7\% de los peruanos sostuvo lo contrario. Según Claudio Fuentes, investigador del ICSO, esto refleja la permanente desconfianza que condiciona la relación bilateral. Aun más, el mismo estudio reveló que una relativa minoría en Chile (36\%) y una gran mayoría en Perú $(60,4 \%)$ perciben que las autoridades del otro país no acatarán el fallo internacional. Finalmente, un $8 \%$ de los chilenos y un $20 \%$ de los peruanos creen posible un conflicto armado.

Está claro entonces que entre Chile y Perú hay desconfianzas y una rivalidad histórica incuestionable. El académico e intelectual peruano José Miguel Flórez habla en un artículo de la existencia de un "problema chileno", en que la dinámica de la relación iría más allá del rol de los Estados, "pues elementos como la 'identidad cultural' o la 'oportunidad política’ jugarían un papel más claro en la dinámica del problema” (Florez, 2007, p. 41). En consecuencia, Chile y Perú han vivido bajo una lógica de rivalidades, desconfianzas, resquemores, resentimientos y desconocimiento mutuo, que ha terminado por condicionar la relación bilateral, haciéndola un juego de suma-cero, en donde el éxito del uno es el fracaso del otro y la debilidad propia ha mutado en fortaleza ajena.

Lo que proponemos en este trabajo es buscar cómo el legado de la Guerra del Pacífico ha favorecido a la construcción de la identidad nacional, al choque de imaginarios y percepciones, condicionando la relación bilateral entre los dos países. Chile y Perú nacieron a la vida independiente sin ser naciones en el sentido moderno de la idea de nación y de Estado-nación proveniente del siglo XIX, ya que como algunos autores sostienen, 
Perú se construiría sobre las bases de una civilización (el Imperio Inca) compuesta por un Estado centralizado, burocratizado y altamente organizado. Las elites que conquistaron la independencia se abocaron a la tarea de construir Estados que llevaran a cabo la edificación de sociedades con un sentido en común, con intereses en común, con historias, visiones y lazos comunes que permitieran conseguir lo que Benedict Anderson llamó la "comunidad imaginada", es decir, la nación (1993).

Dentro de la autoafirmación de ese nosotros está, por cierto, la diferenciación frente a un otro. Nuestra hipótesis es que, en el caso de la construcción de la nación chilena y peruana, el factor del otro ha sido importante, y ha determinado desde el fin de la guerra no solo el modo en que la nación o la nacionalidad ha sido construida, sino que ha llegado a condicionar la vida cotidiana entre ambas naciones.

\section{Perú y la Guerra del Pacífico: Chile como referente y rival}

Para muchos intelectuales peruanos, la Guerra del Pacífico fue la hora cero del Perú moderno, que implicó el colapso absoluto del Estado y el riesgo de su desintegración total. A partir de entonces es otro Perú, y la relación con Chile, que hasta ese momento era más o menos discreta, tomará un rumbo absolutamente distinto.

Pese a que algunos autores, como Sergio Villalobos (2002), han sostenido que las tensiones entre chilenos y peruanos vendrían de los tiempos de la Colonia, nosotros creemos, amparados en el material historiográfico y en las entrevistas a distintos académicos e investigadores tanto en Lima como en nuestro país, que antes del conflicto Chile no habría tenido una importancia especial para Perú. Hasta 1879 tanto la clase política, como el mundo popular peruano, solo habrían visto en Chile poco más que la idea de un lejano, pobre y pequeño territorio al sur del mundo.

La variable Chile era marginal, salvo en algunas cuestiones económicas que generaron tensiones menores. No hubo en los gobernantes del Perú, entre 1821 y 1879, una clara comprensión de que Chile era una contraparte sustantiva y desafiante en las relaciones de poder en el Pacífico Sur (Rodríguez, 2010, p. 21). 
Incluso podemos agregar que las relaciones más bien tuvieron un carácter de colaboración, con momentos importantes como la Expedición Libertadora ${ }^{2}$ o la Guerra con España ${ }^{3}$, en que chilenos y peruanos combatieron contra la intervención europea en las costas de Perú, lo que significó para Chile el terrible bombardeo de Valparaíso en 1866.

Heraclio Bonilla expone con crudeza el trauma de la Guerra del Pacífico. No solo constituyó una derrota militar, sino que además significó una fractura social gravísima, al filo de hacer estallar todas las estructuras sociales del país. De ahí su imborrable presencia en la memoria de Perú. La precaria conciencia nacional del país estaba subordinada así a los intereses de clase: "La guerra nacional entre Perú y Chile ahora daba paso y acompañaba a una pugna interna mucho más significativa, a aquella que oponía las diferentes clases y clientelas políticas de una sociedad profundamente dividida" (Bonilla, 1980, p. 191).

A partir de entonces se reprodujo en Perú una situación ya vivida en los años posteriores a la independencia, en donde el cacicazgo militar apoyado por el terrateniente de turno dio sustento a los distintos poderes. Esta vez, sin embargo, el sustento de apoyo no sería la maltrecha clase terrateniente "gamonalista", sino el ejército de ocupación chileno.

Todas las clases dirigentes estuvieron de acuerdo, una vez concretada la caída de Lima, en acordar la paz con el invasor. El único que no se mostró de acuerdo fue el general Andrés Avelino Cáceres, un poderoso terrateniente quien, desde 1882, emprendió junto a sus montoneras una resistencia obstinada y sangrienta en las sierras andinas no solo contra Chile, sino también contra la oligarquía civilista.

Cuando el coronel Miguel Iglesias lanzó su demanda de paz en Montán, la clase dirigente peruana lo saludó con efusividad. Tanto así que se llegó al punto, según Bonilla, de adherir al ejército chileno, comandado por el general Martiniano Urriola, en el preciso momento en que combatía contra este en el pueblo de Huanta, al mando de Miguel Lazón. Para Bonilla, este hecho constituye quizás "el más trágico epitafio de la historia polí-

2 La Expedición Libertadora fue una operación militar argentino-chilena que tuvo por misión la independencia del Perú. Estuvo bajo el mando del general José de San Martín, formada por tropa argentina y chilena y financiada casi completamente por Chile.

3 Conocida como Guerra del Pacífico en España, fue una contienda bélica que enfrentó a Chile y Perú aliados frente a España entre 1865 y 1866. La causa del conflicto fue la ocupación de las islas peruanas de Chincha por parte de España, que motivó la alianza chileno-peruana, la cual contó con el apoyo político de Bolivia y Ecuador. El conflicto terminó con la retirada de las tropas españolas. 
tica de la clase dirigente peruana" (Bonilla, 1980, p. 196). Tanto la elite dirigente limeña, como las distintas oligarquías regionales, tuvieron similar comportamiento.

Para Heraclio Bonilla es esta una de las mejores imágenes de la fractura y conflicto étnico de Perú, situación a nuestro juicio clave y capital para que el país no haya sido capaz de construir una identidad nacional única e inequívoca. Lo que Bonilla quiere explicarnos es similar a la tesis de Alfredo Jocelyn-Holt respecto a la capacidad del Estado chileno durante el siglo XIX de mantener la estabilidad política sustentada en lo que él llamó "el peso de la noche", es decir, la mezcla de costumbre, represión y carencia de perspectivas por parte de las clases menos favorecidas (Jocelyn-Holt, 1997). En el caso peruano, el equilibrio social era precario y frágil. Una hecatombe como la guerra con Chile hizo saltar en pedazos aquella tranquilidad edificada sobre un volcán.

No solo los indígenas estaban en una situación de dominación, también los negros. En el caso de los primeros, ya libres, y de los chinos, que a causa justamente del fin de la esclavitud negra habían llegado en masa a Perú. Entre 1849 y 1874, llegaron unos 92.130 chinos, según Heraclio Bonilla (Derpich, 1976, pp. 158-162, citado en Bonilla, 1980, p. 204). Se trataba de grupos muy dispersos, numéricamente inferiores. Será el conflicto con Chile el que cambiará esta situación profundamente.

A esto debemos agregar los levantamientos y desórdenes de los indios y mestizos del ejército peruano en desbande, una vez producida la caída de Lima. Estos procedieron al saqueo de las tiendas y a una matanza de propietarios chinos en Lima. En Cañete, la colonia china tuvo que pedir protección diplomática a Inglaterra.

La población indígena de Perú era muchísimo más grande que la de negros y chinos, razón suficiente para que la elite intentara al menos mantenerlos a raya. Sin embargo, era bien difícil que este inmenso grupo de seres humanos, marginados desde la independencia, se comprometieran con la defensa de una nación que casi no reconocían. La caída de Lima provocó muchos levantamientos indígenas, además de la movilización del mariscal Cáceres.

La derrota con Chile produjo en el país un imperativo de definición de las que derivarían más tarde el indigenismo y el mestizaje. Pero una de las primeras conclusiones fue el rol del Estado y su fracaso en constituir una nación, un ente que más allá de ser o no democrático pudiera constituir efectivamente esa "comunidad imaginada" de la que hablaba Benedict Anderson. 
Miguel de Althaus desmenuza el rol del Estado peruano como una suerte de "Estado fallido", incapaz de cumplir con un rol histórico de construcción de una unidad nacional, que el conflicto con Chile puso al descubierto e hizo urgente.

el Estado peruano recién independizado y en los años que siguieron no supo o no pudo convertir, asimilar, hacer suyas, o dar contenido de símbolo nacional a las costumbres, creencias, símbolos comunitarios del indio de la sierra ni del hombre de pueblo en la costa (...) Es que no existía una 'elite' o 'clase dirigente nacional', o sea una burguesía terrateniente o no, que estuviese ligada a la creación de un mercado nacional y a una estructura moderna de la economía (1979, p. 226).

Para Carlos De Gregori, el problema nacional es al mismo tiempo un problema vinculado al tema indígena. Para el autor, la Guerra del Pacífico:

Pone en evidencia la incapacidad del bloque oligárquico dominante para consolidar al Perú como nación, incluso para defender el territorio patrio (...) la oligarquía se ve obligada a replantearse el problema nacional y a encarar seriamente el problema indígena. Por un lado, la catastrófica derrota la obliga a reflexionar sobre la fragilidad o inexistencia de la unidad nacional y, por tanto, la precariedad de su dominio. Por otro lado, se ve en la necesidad de responder, acosada por el desarrollo del capitalismo, la insurgencia del movimiento campesino y popular, y las formulaciones de otras clases: la pequeña burguesía y el proletariado (1978, pp. 22-26).

Además, advierte que el inicio del indigenismo peruano fue uno de los legados más perdurables de la derrota.

La pequeña burguesía va a desarrollar con más fuerza y nitidez el indigenismo propiamente dicho, como ideología de vieja democracia para la forja de una imagen de Perú integral, que abarca los diferentes campos de la superestructura: política, artes, literatura, etc. Estos sectores hacen su entrada de manera agresiva y rotunda luego de la derrota en la Guerra del Pacífico, en la figura de González Prada, quien enfila sus ataques contra las clases dominantes (De Gregori, 1978, p. 34).

Pero, además, la Guerra del Pacífico tuvo otra consecuencia de larga duración: la especial relación que, a partir de entonces, han cultivado chilenos y peruanos. Y ha servido también para aderezar un poco más la construcción de la nación a uno y otro lado de la frontera. 
En el caso peruano hacia Chile, la situación tiene dos componentes: primero, de revancha, de enemistad, de desconfianza hacia un país visto no solo como agresor, sino como amenaza permanente. La indefinición de Tacna y Arica durante 50 años, tiempo en que Chile estuvo tratando de adueñarse definitivamente de ambas, según la óptica peruana, hizo que las heridas de la guerra perduraran por muchos años más.

José Rodríguez Elizondo, periodista, abogado y exdiplomático, gran conocedor de Perú, país en el que vivió casi una década trabajando en importantes medios como Caretas, nos dice que:

Cuando llega la guerra, el Perú consolida una percepción de monocausa, porque los países tienden a simplificar la historia. Y sobre todo luego de una guerra fratricida entre dos países vecinos queda muy claro en la percepción iconográfica cultural, mejor dicho de los pueblos, que hay una sola causa de esto, y esa es Chile. Entonces, todo el rencor se sintetiza en Chile. De ahí viene el calificativo que merece la guerra con Chile de 'guerra infausta', calificativo que no tienen las otras guerras que enfrentó el Perú. Además, Perú perdió mucho más territorios con Brasil que con Chile (comunicación personal, 15 de junio de 2011).

El segundo componente es el de espejo, de admiración. Según lo que indican los distintos autores consultados, en conjunto con los distintos entrevistados, para Perú, Chile siempre ha sido una suerte de referente. Se ha rescatado la experiencia histórica de Chile, el rol de su clase política, su desarrollo institucional, su relativamente exitosa integración, construcción nacional y en los últimos años su despegue económico. Sobre este último punto, basta recordar que al asumir el mando, el ex-presidente peruano Alan García subrayó que su país superará económica y socialmente a Chile a mediano plazo (La Tercera, 14 de mayo de 2008). Una muestra más de que Chile es concebido como principal referente y principal rival, al mismo tiempo.

Rodríguez Elizondo, en su libro Chile-Perú: el siglo que vivimos en peligro, asegura que la Guerra del Pacífico fue un asunto muy especial, "en cuanto fue propinado por los remotos provincianos del sur, por los descendientes de quienes habían recibido con temor o respeto a los chasquis del inca, los curacas del conquistador y los enviados del virrey" (J. Rodríguez, 2004, p. 23). El autor plantea que el tema de la guerra fue un trauma para Perú, país que a partir de entonces inició una dolorosa autoflagelación.

Lo grave - dice- fue que, a poco andar, se convirtió en clave unívoca para la interpretación histórica. Como tal se desarrolló durante todo el siglo XX, transmitiendo amargura a la posteridad y ocultando verdades molestosas (...) La ecuación final indujo, 
entonces, a una historia oficial que equilibraba la previa subestimación de los chilenos con el rencor por la guerra perdida (J. Rodríguez, 2004, pp. 23-24).

Señala además, que el imaginario peruano terminó convencido de que las armas chilenas:

Fueron el factor maligno absoluto de la historia del Perú. Desde tal enfoque, la Guerra del Pacífico emergía como la madre de todas las guerras - 'la guerra infausta' por antonomasia $-\mathrm{y}$ los chilenos asumieron el rol de 'el enemigo de siempre' (J. Rodríguez, 2004, p. 24).

El historiador Joseph Dager, doctor en Historia de la Pontificia Universidad Católica de Chile y director del Archivo Histórico de Lima, sostiene que:

Mi percepción es que, querámoslo o no, aunque nuestras relaciones no se inician con la guerra, al final la percepción que hoy tenemos del otro siempre va a terminar en la guerra. Y mi percepción es porque en el fondo ninguno de los dos consideramos a la guerra como un hecho del pasado. Creo que Chile no termina de darse cuenta que la guerra ya pasó y que por lo tanto no es el país ganador. Fue el país ganador, y ¿quién va a negar que ganara la guerra y cómo la ganó? Pero a veces hay ciertas actitudes, que este diplomático chileno (José) Rodríguez Elizondo definía como actitudes de soberbia frente al Perú, que reflejan que en el fondo se siguen sintiendo ganadores de la guerra, o ciertas actitudes demasiado susceptibles de nuestro lado que, en el fondo, podrían demostrar que seguimos sintiéndonos perdedores de la guerra. Y sin duda, uno ganó y el otro perdió, pero ya fue (comunicación personal, 25 de agosto de 2010).

Cristóbal Aljovín de Losada es historiador de la Pontificia Universidad Católica del Perú y doctorado por la Universidad de Chicago (1996). Él nos dice que el factor Chile es:

Bastante importante a partir de la Guerra del Pacífico, no antes. A partir de la Guerra del Pacífico la elite criolla peruana y ciertos sectores populares pensaron el país a partir de la derrota y constantemente nos estamos mirando frente a Chile. Está esa idea de que Chile tiene una identidad nacional más fuerte que el Perú, entre otras. Antes de la guerra, no. Durante y después de la guerra, la nación peruana se define en relación a la chilena (comunicación personal, 28 de agosto de 2010). 
Aljovín de Losada destaca uno de los hechos menos recordados por la historiografía chilena, con algunas excepciones como el historiador Sergio González (2008): el asunto de Tacna y Arica y el intento de chilenización llevado a cabo por las Ligas Patrióticas en esa zona.

El artículo tercero del tratado de Ancón ${ }^{4}$ estipulaba que (el asunto de) Tacna y Arica se tenía que resolver a través de un plebiscito, y la negociación duró entre 1883 a 1929. Fueron décadas y décadas en que el Perú consideró que la guerra fue muy injusta y diversos sectores consideraron que Chile estaba jugando sucio en las negociaciones. Es una suerte de tratado de Versalles que no cerró bien el debate. Entonces, no solo es la guerra, sino también el proceso de negociación de Tacna y Arica, son 40 años en que cada semana salían anuncios con parte de la negociación. El artículo tercero es muy claro y dice que tenía que organizarse un plebiscito a los diez años y nunca se organizó. Y toda la política exterior del Perú estaba orientada a la recuperación de Tacna y Arica. Te darás cuenta de esa dimensión, no fue una guerra que se cerró, sino que continuó hasta 1929. Entonces, son dos factores: la guerra y todo el proceso de negociación pos-Tratado de Ancón. Es importante conjugar las dos cosas para entender cierta cultura antichilena del Perú (comunicación personal, 28 de agosto de 2010).

Julio Cotler, afamado y prestigioso sociólogo del Instituto de Estudios Peruanos, nos cuenta que:

Desde la gran derrota, para los grupos intelectuales fue siempre la confrontación: por qué Chile sí y Perú, no. Chile había sido una capitanía perdida, un país chiquito. En cambio, nosotros habíamos sido la capital del imperio, la capital del virreinato, y con la guerra recién vinieron a hacer el descubrimiento de que ahí en Chile hubo una clase (social alta) y aquí no la hubo. Que aquí esto era una masa amorfa, allá en Chile había una cuestión orgánica, hubo Estado (comunicación personal, 7 de septiembre de 2010).

El trauma de la derrota indujo a los peruanos a buscar explicaciones que les permitieran comprender tamaña catástrofe. Y el fantasma de Chile y su devenir se hicieron presentes como antagonista y referente:

4 El Tratado de Ancón, firmado entre Chile y el Perú el 20 de octubre de 1883, puso fin a la Guerra del Pacífico. Entre sus disposiciones estipuló que Chile se quedaba a perpetuidad con la provincia de Tarapacá, y que Tacna y Arica lo estarían por un período de diez años, al cabo de los cuales se debería realizar un plebiscito que decidiera su suerte. El plebiscito nunca se realizó y Chile mantuvo bajo su soberanía a ambas ciudades hasta el Tratado de 1929, que devolvió Tacna al Perú y ratificó la soberanía chilena en Arica. 
Permanentemente la gente te va a hablar aquí de (Diego) Portales. Allá hay Estado, yo mismo lo digo, he puesto tantos ejemplos de la vida cotidiana, del respeto a la autoridad, a las reglas. No es el país perfecto, pero de que relativamente hay cosas que forman parte de una vida republicana, estatal, mientras que acá no. Entonces toda la vida ha habido esa confrontación. Por un lado es el país que nos derrotó, que siempre nos gana, es el país que nosotros aspiramos a ser. Lo tienes a Alan García, que dijo que hay que seguir los pasos, hay que ser como ellos. Entonces, hay cierta ambivalencia (comunicación personal, 7 de septiembre de 2010).

Eduardo Toche, historiador, investigador y analista político del Centro de Estudios y Promoción del Desarrollo del Perú, dice que:

En efecto, la Guerra del Pacífico es el punto fundante del Perú moderno. Tenemos, si nos ponemos a hacer un esquema, a Chile como el punto de referencia hacia afuera, sí lo es. La guerra fue una cuestión de si podías sensibilizar fibras patrióticas en un país, bien difícil de movilizarlas por sus características. Todos se sienten de alguna manera identificados con una amenaza, y la amenaza se configuró por este sentimiento de los sectores dirigenciales que es volcada hacia el sistema educativo. En la educación eso se cultivaba y lo que se transmitía era esto, aquí hay una herida y una cuestión por saldar (comunicación personal, 3 de septiembre de 2010).

Por su parte, José Robles Montoya, oficial de Ejército ${ }^{\circledR}$, máster en Administración de Empresas, analista de seguridad y defensa nacional, autor de "De la disuasión a la cooperación: dos siglos en la relación Perú-Chile", publicado por la revista Fuerzas Armadas y Sociedad, en 2006, sostiene sobre el papel de Chile en la construcción de la nación en Perú que:

Lo de Chile, más que una construcción, ha sido un pretexto que se ha utilizado para invocar nacionalismos. A mediados de la década de 1910 la idea de Chile como principal responsable de la creación de la nación peruana dejó de tener fuerza, salvo en Tacna. En Tacna todavía mantiene algún que otro hijo de plebiscitario que tiene enraizada esa traición. Ya después de las tres primeras décadas después de la guerra el problema de Chile se empezó a utilizar como pretexto. Creo que Chile fue después de los años 50 el pretexto para aglutinar, que cada vez tiene menos resultados porque la gente está pensando, estamos comenzando a ver que no solamente es una cuestión de entrarnos a trompear (comunicación personal, 2 de septiembre de 2010). 
La Guerra del Pacífico demostró, además, que Perú tampoco poseía un proyecto nacional coherente. Desde entonces, el contraste con Chile ha sido permanente, ya que Perú empezó a ver a nuestro país como un territorio pequeño, pobre y lejano, pese a lo cual tuvo la virtud de encontrar un rumbo fijo, apuntar hacia él y conseguir sus objetivos. Eusebio Quiroz Paz-Soldán lo expresa de manera muy diáfana:

Chile mostró una sólida coherencia entre sus propósitos estratégicos y políticos con la forma como conducía la guerra, esta, como desenvolvimiento militar, apoyaba en última instancia, los propósitos políticos, vale decir, el expansionismo territorial y la hegemonía marítima. Con esto Chile llevó adelante la guerra. En cambio el Perú no tuvo, en esos críticos momentos, la necesaria unidad, el proyecto nacional, un plan que coordinara la conducción política, los objetivos nacionales y la acción internacional (1984, p. 31).

¿Qué serían estos objetivos nacionales? El propio Quiroz Paz-Soldán nos da una pista:

Un país no puede avanzar hacia la consecución de su destino si no tiene metas, propósitos, objetivos, planes. Sin brújula orientada no se llega a ningún punto; de la misma suerte un país a la deriva, sin definir sus objetivos, tampoco marcha seguro, a ninguna parte. El plan guía y marca rumbos (1984, p. 31).

Miguel de Althaus nos da otra clave para entender por qué Chile se constituye a partir de entonces en un elemento tan importante para la vida peruana:

La guerra con Chile tiene especial importancia en el desarrollo de la nacionalidad. Es una guerra con características que en el Perú no tenía precedentes porque involucra más que ninguna otra a las distintas capas de la población. La derrota del ejército regular obliga a la conformación apresurada de regimientos de civiles de los más diversos estratos sociales y de las edades más variadas que se explica por la existencia de una identidad nacional que defender. La ocupación de Lima y de distintos valles de la costa por el ejército chileno, y sus incursiones a la sierra produjeron entre distintos pueblos la aversión al extranjero como símbolo y saqueo. Pero allí también se reveló la debilidad del Estado peruano como forjador de una nacionalidad que incorpora a pueblos cuando percibimos la adhesión de los maltratados culíes chinos al ejército, y la diversa participación de la población de la sierra, todavía no bien estudiada, entusiasta con Cáceres, otras veces indiferente sin él (1979, p. 227). 
Carmen Mc Evoy no se queda atrás y sostiene que,

Podemos afirmar, sin temor a equivocarnos, que la derrota frente a Chile fue el peor revés que sufrió el país luego de su destructiva guerra por la independencia (...) En pocas palabras, las bases económicas, políticas, ideológicas e incluso geográficas del sueño republicano fueron erradicadas violentamente por la secuela de destrucción física y moral que dejó la guerra (1997, p. 252).

El hecho de que la guerra - justamente con Chile- haya provocado el gran colapso peruano del que hablaba Bonilla ha hecho que, especialmente las elites peruanas, tengan una fijación con Chile, no tanto por revanchismo, sino más bien por una mezcla de admiración y referencia. El hecho de que esto haya surgido de la guerra le da a este sentimiento un cariz amargo, que suele verse como revanchista. Al ver que Chile es un país suficientemente organizado, estructurado, coherente, con un objetivo y un discurso, los peruanos han estado desde entonces buscando su propio camino chileno, su propia creación de proyectos, objetivos, idearios y sentidos comunes, que les llevarán a un estadio de desarrollo superior. En Perú, la máxima es algo así como "Si Chile lo hizo, ¿por qué nosotros no?", en un lejano resabio de la superioridad virreinal ante la humildad de la lejana colonia sureña. Nuevamente Quiroz Paz Soldán:

El proyecto nacional - del que hablamos - no es circunstancial, no es tampoco un asunto de emergencia, se trata de un proyecto orgánico, complejo, que integra los aspectos fundamentales de la existencia del país con la mira principal de conseguir la unidad nacional y la de trabajar alrededor de objetivos esenciales cuya consecución debe ser interés de todos los peruanos (1984, p. 32).

Heraclio Bonilla, haciéndose parte de quienes piensan que la guerra con Chile significó para Perú el inicio de su camino moderno, dice:

La forma como el Perú se "reconstruye", es decir el nuevo alineamiento interno de sus diferentes fuerzas sociales, así como la nueva naturaleza que reviste su inserción en el mercado internacional, hace de los años inmediatos de la posguerra el punto de partida del ordenamiento del Perú contemporáneo (1980, p. 223).

Julio Cotler sostiene que hoy Chile: 
Para la gente, cierta intelectualidad, ciertos políticos, es una presencia. Para otra gente es la amenaza. Hay un rechazo muy fuerte porque se ve como una amenaza, que se quieren agarrar Arequipa, que porque no tienen agua se van a querer agarrar el lago Titicaca (...) El mundo de la fantasía y el temor está permanentemente ahí. Al mismo tiempo, es la envidia para unos y, para otros, el modelo a seguir. Si los militares dicen 'un general en Chile gana el doble al de acá, 'en Chile hay esto, aquí no,' 'en Chile esto otro'. Siempre el punto de referencia y al mismo tiempo el punto de contra (comunicación personal, 7 de septiembre de 2010).

Cotler establece que, de no haber existido la Guerra del Pacífico, nuestro país sería igualmente visto como referente para Perú:

La institucionalidad chilena es lo que todo el mundo añora. Porque no es únicamente al nivel del Estado ni las cosas militares, es la vida cotidiana. Chile es un modelo a seguir, para el sector empresarial, el sector político, el Apra, es un modelo a seguir. Estabilidad institucional, inversiones extranjeras, etc. (comunicación personal, 7 de septiembre de 2010).

Joseph Dager dice que:

Chile, dentro de la construcción del imaginario popular peruano, es siempre un referente. Lo ha demostrado el mismo presidente (Alan) García. En su campaña presidencial, una de las cosas que decía con mucha reiteración era que él quería que el Perú fuera mejor que Chile. Lo cual está muy bien, ¿quién puede decir que un deseo de esa naturaleza esté mal? Pero obviamente no tiene el mismo impacto decir 'quiero que el Perú sea mejor que Chile' que decir 'quiero que el Perú sea mejor que Brasil', aunque Brasil esté mejor, o 'mejor que Suiza'. Si vamos a ser mejor que Chile la cosa es un poco diferente. Chile está mucho más presente en la construcción de este imaginario nacional. No es un constructor, no contribuye a la edificación nacional, pero digamos que la guerra, la ocupación posterior, el haberse quedado con territorios, la misma soberbia, hacen que en el discurso ideológico-político nacionalista del XIX y de hoy la variante de Chile siempre está ahí. Es un tema que, tanto en el Perú como en Chile, rinde frutos. Zanjar, arreglar totalmente el problema con Chile, nos haría perder un motivo, y creo que a Chile también. Creo que es fundamentalmente por eso por qué se han dejado pendientes algunas cosas (comunicación personal, 25 de agosto de 2010).

Cristóbal Aljovín de Losada insiste en el aspecto referencial que Chile ha tenido para Perú, especialmente respecto a su formación institucional.

Ha habido varios momentos en que el Perú vio a Chile como un prototipo. La lectura del siglo XIX es por qué el Perú no tuvo un Portales. Esa estabilidad decimonónica chilena. Lo 
que es verdad es que Chile ha implicado una serie de transgresiones en torno al Perú, obviamente con fuerte antichilenismo, pero con mucha admiración también (comunicación personal, 28 de agosto de 2010).

\section{Chile y la Guerra del Pacífico: entre la soberbia y el mito de la nación guerrera}

La Guerra del Pacífico tuvo lugar entre 1879 y 1883. Para Chile significó un antes y un después en la definición propia, la autoconcepción e identidad nacional, y condicionaría desde entonces la relación con peruanos y bolivianos. Una de sus primeras consecuencias fue la incorporación definitiva de los sectores populares como actores de esta construcción, aunque siempre dentro de la lógica de la elite.

Se necesita por de pronto integrar en la idea de nación además de los sectores medios al pueblo, al "roto", que ha sido uno de los artífices del triunfo (en la Guerra del Pacífico) (...) Todo ello conforma un clima que estimula la reelaboración de la identidad nacional en una perspectiva de cohesión e integración social. Una identidad que permite sumar aunque sea simbólicamente a los sectores medios y populares, incluso a los indígenas, y que permite también corregir el imaginario liberal de ciudadanos que no eran tales (Subercaseaux, 2010, p. 71).

Después de la victoria surgió el roto chileno como elemento identificador de los sectores populares, al mismo tiempo que Perú pasaba indirectamente a formar parte del imaginario como un otro, que sustituyó desde ese momento a España como la "nación enemiga" por antonomasia, y que junto al pueblo mapuche (el 'otro' interno) ayudó a apuntalar el diferenciador del 'nosotros'.

En los casos de Chile y Perú ha sido la guerra, a falta de otro elemento identitario de mayor profundidad histórica y social, lo que ha contribuido a generar este espacio colectivo llamado identidad y nación.

Para América Latina este aserto cobraría una relevancia fundamental, en la medida que ante la ausencia de un capital histórico necesario para fundar las naciones en el siglo XIX, las guerras posibilitarían precisamente una 'solución iconográfica' para crear un sentido de comunidad, generando un lazo de pertenencia a un cuerpo social mayor - la nación-, definida también por oposición a ese 'otro' que se combate (Cid, 2009, p. 233). 
Además de la integración forzada de la nación en casos de guerra, la visión del otro toma una dimensión aún mayor. La nación se reunifica a sí misma, provocando o acentuando la exclusión de la otredad. Así llegamos a un enfrentamiento de un nosotros frente a un otro, que juega un papel capital en la construcción de los estereotipos y sus elementos simbólicos y discursivos. La autoimagen y la imagen del otro, en un contexto bélico, son importantísimas en las representaciones nacionalistas de las guerras. El Estado socializa una serie de discursos e imágenes cuyo papel es justificar y ennoblecer las causas del conflicto, apelando a la emotividad de la sociedad. Para Bernardo Subercaseaux, la Guerra del Pacífico es:

Sin duda la mitología retrospectiva más importante del Chile moderno. Probablemente más significativa, incluso, que la Independencia. Una fuente de patriotismo que nutre desde la lira popular hasta los ritos y conmemoraciones cívicas y militares. Es también el tema de uno de los mayores éxitos radiofónicos y editoriales del siglo XX: el radioteatro "Adiós al Séptimo de Línea”, y la novela homónima, de Jorge Inostroza. La Guerra del Pacífico, ha devenido, por ende, un ícono de lo nacional-popular en sentido gramsciano, de allí que sea posible llamarla la 'guerra de Chile' (1997, p. 197).

Subercaseaux analiza al respecto la obra de Gonzalo Bulnes sobre la Guerra del Pacífico, en la que llama la atención por su afán nacionalista aristocrático. Señala que Bulnes olvidó algunos detalles importantes del conflicto, como el reclutamiento forzoso de niños y presos, las disputas internas en el seno de las tropas nacionales, enfermedades venéreas, deserciones y fugas, alcoholismo, los abusos varios cometidos por las tropas, el saqueo de la Biblioteca Nacional de Lima y el abandono de muchos excombatientes. La Guerra del Pacífico es para Bulnes:

Una guerra de la nación en armas (lo que se 'dice' pero no se 'muestra'), conducida por la elite, por miembros de las familias patricias a quienes el historiador le otorga casi todas las medallas. Ahora bien, los rasgos con que se describe a estas figuras apuntan a la sobriedad, al espíritu de trabajo y sacrificio de la antigua aristocracia del viejo Chile (Subercaseaux, 1997, p. 201).

Destaca que Bulnes se hizo eco de aquel mito sobre la excepcionalidad de Chile. Utilizando una visión etnocentrista, Bulnes haría homenaje a una supuesta "superioridad de la historia de Chile" respecto a peruanos y bolivianos: "Lo que venció al Perú —dicefue la superioridad de una raza y la superioridad de una historia: el orden contra el desorden: un país sin caudillos contra otro aquejado de este terrible mal" (Subercaseaux, 
1997, p. 201). La importancia de la guerra es que activa, por primera vez, una idea de una supuesta raza chilena.

La emergencia y uso de la categoría 'raza chilena' en un determinado momento histórico del país puede explicarse por distintos factores. Con la Guerra del Pacífico y más tarde con el Centenario, la 'emocionalidad de la patria' se reactiva y requiere de alguna instancia para productivizar una mayor cohesión social (Subercaseaux, 1997, p. 202).

En este punto debemos hacer referencia a las teorías del nacionalismo étnico de Walker Connor, quien en su texto Etnonacionalismo hace un análisis de la identidad nacional en torno a su esencia psicológica y emocional, que según él tiene un valor fundamental en la identidad colectiva nacional. "La esencia de una nación no es tangible —dice- sino psicológica. Es una cuestión de actitudes y no de hechos" (Connor, 1998, p. 45). Una comunidad necesita sentirse parte de un todo, necesita creer que forma parte de una comunidad particular y definida, diferente del resto no solo en su tangibilidad, sino también en su esencia espiritual.

Un requisito para la existencia de la condición de la nación es la idea o creencia popular en que el propio grupo es único, especial, en un sentido muy vital. Cuando no se da esta convicción popular, el colectivo no pasa de ser un grupo étnico (...) la nación no existirá en tanto en cuanto una proporción elevada de sus miembros no sean conscientes de su diferenciación (Connor, 1998, p. 45).

La idea de la raza chilena, construida en parte a la diferenciación con un otro como Perú, es un elemento clave en la identidad nacional chilena y constituye ciertamente un elemento emotivo de esta identidad y su particularidad:

Siendo así que la esencia de la nación es una cuestión de actitudes, las manifestaciones tangibles de la diversidad cultural solo son relevantes en la medida en que contribuyen a crear un sentimiento de particularidad (...) Así pues, el factor esencial para determinar la existencia de una nación no son las características tangibles de un grupo, sino la imagen que este se forma de sí mismo (Connor, 1998, p. 45).

El sentimiento de particularidad en el caso chileno tiene, pues, en el otro, en Perú, su definición propia. Este elemento clave, de ser realmente comprendido y asimilado, nos permitirá, según creemos, comprender gran parte de la enmarañada madeja que han sido desde entonces las relaciones chileno-peruanas. Comprender esto será trascendental para plantear a futuro nuestras relaciones con el vecino. 
La incorporación violenta de nuevos territorios al país, como las provincias del norte luego de la Guerra del Pacífico y de la Araucanía después de la intervención armada del Ejército en la zona, hicieron posible el surgimiento de una definición política de un nacionalismo y de una nación en términos geopolíticos, que hasta ese momento solo había sido advertido por muy pocos. El territorio es la base material que distingue y separa políticamente a la nación de sus vecinos.

El territorio tiene, por ende, un significado moral, político y hasta metafísico. En esta perspectiva hay que entender la preocupación constante por resaltar la Guerra del Pacífico y por los problemas limítrofes pendientes, o el propósito de un discurso que buscó chilenizar como ciudadanos a los mapuches... (Subercaseaux, 1997, p. 118).

La Guerra del Pacífico ratificó lo que el sociólogo Jorge Larraín ha llamado la "versión militar-racial" de la identidad chilena. Para nosotros es simplemente una reactualización, una relegitimación de la supuesta identidad guerrera de Chile, país heredero de la Guerra de Arauco y que se habría formado al alero de una constante atmósfera militar.

Larraín explica que la influencia de la visión militar en la identidad chilena tiene una relación directa con la educación. Para nosotros, en el caso chileno ambas han sido las principales herramientas del Estado en esta empresa:

La versión militar de la identidad chilena ha tenido una representación destacada en la enseñanza de la historia en las escuelas y colegios de Chile hasta muy recientemente (...) la guerra de Arauco, la guerra contra la Confederación Perú-Boliviana y la guerra del Pacífico figuran como tres hitos decisivos en la formación de la identidad chilena. En especial el texto de (Francisco) Frías Valenzuela, en el que se formaron generaciones de estudiantes chilenos, reafirma la idea de que la guerra de Arauco conformó una identidad en que sobresalen los valores de resistencia, valentía y sobriedad. Las dos guerras posteriores habrían sido cruciales para consolidar nuestra unidad territorial y nacional, pero además reflejarían el triunfo de la identidad chilena sobre otras identidades. La afirmación de la identidad chilena pasó necesariamente por la derrota del enemigo (2001, pp. 156-157).

Este punto es muy importante de destacar ya que siempre en la construcción de la identidad existe un 'otro' por medio del cual apuntalar el nosotros. Y este otro puede ser un opuesto referencial (del que podemos aprender) o negativo (que signifique una amenaza). La identidad chilena se ha ido formando, así, a través de unos 'otros' que han jugado el rol de diferenciadores de lo chileno, pero también de espejos dependiendo del caso. Entre los espejos, el primero de ellos fue España, la madre patria que "durante más 
de tres siglos fue nuestro 'otro' más significativo, del cual dependeríamos hasta en los más mínimos detalles, y cuyas expectativas políticas, culturales y religiosas llegaron a ser nuestras propias autoexpectativas" (Larraín, 2001, pp. 262-263).

A partir de la independencia, el rol de referente que había hasta entonces desempeñado España fue reemplazado por Inglaterra y Francia. Mientras Inglaterra pasó a ser un referente en el campo político-económico, la influencia francesa se hizo sentir con más fuerza en las letras y la cultura. Después de la Segunda Guerra Mundial son los Estados Unidos los que relevan a ingleses y franceses en el imaginario referencial, manteniendo esa posición de privilegio hasta hoy. Por otro lado, en varios períodos de la historia nacional, como en el siglo XIX con los mapuches, y durante la dictadura de Pinochet con la militancia de izquierda, existieron "enemigos internos oficiales" que jugaron el rol del 'otro', encarnadores de la 'antipatria' o 'antinación'. Son los 'otros' como oposición. En el caso del pueblo mapuche se desató una rivalidad profunda durante el siglo XIX que terminó con la invasión de la Araucanía por parte del ejército chileno, y que dejó para la posteridad desprecio, racismo y otros rasgos antimapuches en el pueblo chileno.

Pero, sin embargo, son dos los elementos de oposición más destacados: Bolivia y Perú, los antiguos enemigos de la Guerra del Pacífico y que son, según Larraín, considerados desde entonces "los enemigos naturales de Chile". El sociólogo tiene al respecto una opinión clave para nuestro estudio:

Frente a ellos el chileno medio tiene un sentimiento de orgullo y superioridad. Se les denomina despectivamente 'cuicos' (sic), y se tiene una pobre impresión de su capacidad y de su cultura. El hecho de ser países con grandes mayorías indígenas, con una fuerte cultura autóctona no plenamente europea, reafirma el sentido racista y antiindígena, muchas veces bien camuflado, que existe en Chile. Esta actitud se aprende ya en los colegios en el estudio de la historia (Larraín, 2001, p. 265).

¿Es Perú un ingrediente clave en la construcción de nuestra nacionalidad? Jorge Larraín cree que sí lo es.

Perú es para Chile el 'otro', aquel que es distinto a mí, a un nosotros. El Perú cumple ese rol para Chile, de constituir un elemento diferenciador, en donde el chileno puede verse a sí mismo. Es algo que sucede no solo con la nación, sino además con la religión, la política, el fútbol. Además, es visto desde Chile como inferior, Chile se ve a sí mismo como superior ante el Perú (comunicación personal, 18 de abril de 2011). 
Larraín hizo además una interesante precisión, que puede explicar el porqué de la tirantez del chileno - el ciudadano común o un miembro de la elite y la clase políticaante la sociedad peruana:

En Chile hay mucho temor hacia el Perú, no por creer que ellos nos van a venir a ganar en una guerra, sino porque el 'factor Perú' hace que Chile siga teniendo algo pendiente, algo no resuelto. Además, Chile ve al Perú como un factor revanchista, como un país que aún no supera el tema de la guerra. Lo dice el propio Ollanta Humala, por ejemplo (comunicación personal, 18 de abril de 2011).

Concuerda con él Bernardo Subercaseaux, quien apunta al legado de la Guerra del Pacífico:

de alguna manera la confrontación con el Perú en la segunda mitad del siglo XIX y comienzos del siglo XX ha sido un foco de nacionalismo chovinista para Chile. Hay un racismo contra los peruanos y que se construye en esos momentos. Aparece Chile como un país de excepción en relación con el Perú. Estos problemas limítrofes y lo que pasó con las guerras han insuflado un ejército que se dice 'jamás vencido', y no fue verdad porque fue vencido en la época de Balmaceda. Entonces, esa idea de victoria del ejército es falsa, y viene de una construcción identitaria del ejército en base a los problemas con el Perú. El Perú ha sido un factor en el chovinismo nacionalista que de alguna manera se prolonga hasta hoy (comunicación personal, 6 de mayo de 2011).

Además, Subercaseaux apunta al interés de explotar esta situación de posguerra como un símbolo, utilizado como parte del disciplinamiento social:

Hay una historia de la guerra chilena y otra peruana. La historia peruana no está en el imaginario chileno. Cero. Entonces, no tiene presencia positiva el Perú en Chile, es una presencia por descarte. Lo vencimos, está al lado, es el 'otro'. Pero esa visión de ese otro no está internalizada ni siquiera en la historiografía chilena. Porque cuando hay dos países en guerra, la visión del vencedor es la que prevalece, sencillamente eso. Y esas son formas de disciplinamiento social también (comunicación personal, 6 de mayo de 2011).

Recordemos que para el filósofo francés Michel Foucault, el disciplinamiento es un medio, es la generación de un lazo social que permite el control y la sujeción funcional de ciertos sectores para el mantenimiento de un cierto orden económico, político y social: 
El momento histórico de las disciplina es el momento en que nace un arte del cuerpo humano, que no tiende únicamente al aumento de sus habilidades, ni tampoco a hacer más pesada su sujeción, sino a la formación de un vínculo que, en el mismo mecanismo, lo hace tanto más obediente cuanto más útil, y al revés. Fórmase entonces una política de las coerciones que constituyen un trabajo sobre el cuerpo, una manipulación calculada de sus elementos, de sus gestos, de sus comportamientos (2002, p. 126).

Concordamos con la visión de Foucault respecto a que el disciplinamiento social es una herramienta de los sectores más acomodados para imponer, por medio de distintos medios, una anatomía política o una mecánica del poder, como la define el filósofo francés, que le permitan mantener bajo su control a la sociedad.

Una 'anatomía política', que es igualmente una 'mecánica del poder', está naciendo; define cómo se puede hacer presa en el cuerpo de los demás, no simplemente para que ellos hagan lo que se desea, sino para que operen como se quiere, con las técnicas, según la rapidez y la eficacia que se determina. La disciplina fabrica así cuerpos sometidos y ejercitados, cuerpos «dóciles». La disciplina aumenta las fuerzas del cuerpo (en términos económicos de utilidad) y disminuye esas mismas fuerzas (en términos políticos de obediencia). En una palabra: disocia el poder del cuerpo; de una parte, hace de este poder una 'aptitud', una 'capacidad' que trata de aumentar, y cambia por otra parte la energía, la potencia que de ello podría resultar, y la convierte en una relación de sujeción estricta. Si la explotación económica separa la fuerza y el producto del trabajo, digamos que la coerción disciplinaria establece en el cuerpo el vínculo de coacción entre una aptitud aumentada y una dominación acrecentada (Foucault, 2002, pp. 126-127).

El discurso pos-Guerra del Pacífico se enmarca, para nosotros, en este ideario de dominación acrecentada, que a partir de entonces sirvió como discurso aglutinador y de identidad para la nación chilena, pero al costo de condicionar para siempre sus relaciones con Perú.

Subercaseaux concuerda que Perú no tiene importancia en el imaginario chileno más allá de esto, un símbolo poderoso, pero solo símbolo al fin y al cabo. Por lo tanto, su persistencia tiene explicación por la perduración de ese discurso nacionalista construido entre la Independencia y la época del Centenario.

Hay una persistencia de un discurso nacionalista añejo. No hay una puesta al día en un mundo que ha cambiado y que las cosas son diferentes, que el aquí y el allá son distintos. Y de Perú también, de América Latina prima un poco eso. El sentido de soberanía tradicio- 
nal, nacionalista, estrecho. No se ve la perspectiva que desde el punto de vista económico la globalización, los mercados comunes permitan fortalecer. Cada uno trabaja por su cuenta (comunicación personal, 6 de mayo de 2011).

En esto último coincide el historiador Eduardo Cavieres, cuando señala que el discurso nacionalista:

Ha tenido una evolución, pero el gran problema histórico que tenemos, no solamente en Chile sino en América Latina, es que estamos utilizando estos lenguajes, símbolos y significados de estos conceptos desde el punto de vista del Estado nacional del siglo XIX, que es la gran diferencia que tenemos hoy día con la Unión Europea, que no ha perdido la soberanía que les compete a cada Estado, pero la han modificado en términos de sus aplicaciones. Los Estados hoy día ceden soberanía cuando permiten el libre tránsito de las personas, moneda común, políticas económicas de Estado. En América Latina estamos hablando de un concepto de soberanía propio del siglo XIX, muy contradictorio porque hablamos de soberanía territorial, pero en Chile nuestros puertos están privatizados. Hace 50 años eso era imposible porque los puertos son posiciones estratégicas. Entonces, aquí hay un problema de que el Estado precisamente por el desarrollo que ha tenido ha sido bastante poco tolerable a cambios profundos en términos de su propia consistencia (comunicación personal, 29 de abril de 2011).

Además, le baja un poco el perfil al factor Perú como constructor de la nación en Chile, aunque no descarta su trascendencia. Para el historiador, el país vecino no tendría mucha importancia:

Excepto desde el punto de vista de la alteridad o construcción de alteridades. Y esto indudablemente tiene que ver con los alcances de la Guerra del Pacífico y todo el nacionalismo cultural del siglo XX, en el sentido de que para Chile ha sido bastante dificultoso, por una parte, tener los mismos problemas sociales que el Perú, pero por otro lado sentirse efectivamente victorioso en la guerra quizás más dura y de mayores proyecciones en torno al imaginario latinoamericano. El sentirse victorioso (Chile indudablemente ganó la guerra) es una especie de carga histórica al revés. Es decir, como ganamos la guerra, tenemos que seguir siendo exitosos. Y eso ha significado que cuando pensamos a Perú o a Bolivia nos sintamos que no solamente hemos sido exitosos, sino que seguimos siendo más exitosos (comunicación personal, 29 de abril de 2011).

Lo notable de esta situación radica en el hecho de que, para nosotros, la Guerra del Pacífico refuerza la identidad nacional en el sentido de cumplir el rol de reactualizador 
moderno del mito militar que el país cultivó desde la independencia. Desde La Araucana, de Alonso de Ercilla, que la cuestión militar en Chile ha sido rescatada por el poder, reprocesada y acomodada a sus intereses y presentada a los demás sectores y actores sociales como parte fundamental de la chilenidad. Para nuestro análisis, es la Guerra del Pacífico un torrente de símbolos que refuerzan este mito identitario militar. Más que Perú en sí, es la guerra, el conflicto, sus hazañas y desventuras lo que quedó para siempre en el imaginario colectivo nacional. No por nada la cuenta presidencial se hace cada año los 21 de mayo.

\section{Conclusiones}

La Guerra del Pacífico ha perpetuado un sinnúmero de desencuentros entre ambas naciones, que junto a la demanda permanente de un reconocimiento desde Perú para que Chile efectúe gestos, se mezcla con la visión chilena de un supuesto revanchismo peruano. Así, cualquier avance queda subyugado por estos resquemores y desconfianzas.

La guerra fue para Perú un verdadero cataclismo que sacudió las estructuras más profundas del país, provocando el colapso del Estado. Chile se ha transformado en un polo de atención en dos sentidos: ha pasado a ser visto como una amenaza para Perú. El revanchismo peruano es algo presente en la vida cotidiana de algunas personas y es un elemento para algunos grupos de poder con notable influencia en los medios y en la política. El simbolismo de la guerra está presente en todos los rincones del país. Y por cierto, eso terminó formando parte de la construcción de una religión civil. El Día de la Bandera es el 7 de junio (aniversario de la derrota en el Morro de Arica en 1880), mientras que el 8 de octubre (aniversario del combate en Angamos), es un día feriado en el Perú. Si bien es cierto que Chile es un país donde la derrota es fuente de memoria histórica emotiva, creemos que la carga de simbolismo es mayor en Perú, ya que, a diferencia de Chile, el efecto de la derrota le da a estas celebraciones peruanas un aire de rescate de la dignidad, antes que resaltar un heroísmo épico, en una gesta que terminó en victoria, como en el caso chileno.

Por otro lado, Chile se ha convertido en un referente para Perú. Como señalaba Julio Cotler, Chile encarna lo que Perú siempre ha querido ser. La admiración sincera por la institucionalidad chilena; la añoranza de una figura como Portales; el paso de la antigua Capitanía General pobre, lejana y olvidada, a ser un interesante, aunque imperfecto, modelo de desarrollo, han hecho que los peruanos no puedan dejar de mirar al sur. La 
cita del presidente Alan García de superar a Chile es toda una biografía. El papel de Chile, más que simbólico, ha terminado siendo referencial, que evoca lo peor de la historia peruana, pero al mismo tiempo una suerte de ejemplo de lo que el país es capaz de hacer.

En cuanto al rol del Perú como constructor de la nación chilena, debemos concluir que su papel ha sido importante, pero no decisivo. El gran conflicto bélico del siglo XIX no dejó en Chile los grandes traumas que dejó en Perú. El tema de la guerra se unió al discurso militar del cual hablaba Larraín (2001), actualizándolo, reinventándolo y dándole un cariz diferente. El antiguo mito del chileno hijo del español y mapuche, en medio de la Guerra de Arauco, que legó la virilidad, entrega, sacrificio y esfuerzo por un ideal mayor (en este caso la patria), quedó de manifiesto en la conflagración de 1879.

La guerra apuntaló el discurso nacional militar chileno, que había estado presente a través de La Araucana por medio de la educación y la transmisión de los medios. El roto chileno fue ensalzado, a contrapunto del cholo y el indio peruano, y según este discurso Perú pasó a ser, a ojos de los chilenos, el otro débil, cobarde, derrotado, incapaz de defender su rica tierra ante las implacables armas de un pueblo pobre, pero joven y aguerrido. La larga duración del asunto Tacna y Arica dilató el fin del conflicto por décadas, arrastrando esa visión por años debido a la necesidad de mantener el país cohesionado en previsión de un nuevo conflicto con el Perú. La carga emotiva, emocional y propagandística de ese hecho, en momentos en que la intelectualidad chilena reevaluaba la idea de nación, incorporando un discurso étnico o de raza, terminó por consagrar esa negativa visión de Perú y otorgarle un papel especial en la idea de nación que tenemos los chilenos.

Esa idea mutó en un sentimiento de arrogancia. Se trató de una autopercepción de máximo orgullo que, combinada con las necesidades de mantener lo recientemente ganado por las armas, fue reforzado por el Estado chileno. Para nosotros esa es la razón de que Perú, país que no juega un rol de referente para Chile, sí hace el papel del símbolo. Además, el mismo derrotero histórico chileno hace que mantenga una postura reactiva frente a Perú, que al mismo tiempo — como señaló Larraín (2001) — tiene mucho de temor, temor a reevaluar lo ganado, a perderlo.

Sería de una tremenda importancia para el futuro de ambos países superar estos discursos y visiones antagónicas que impiden un desarrollo mutuo, cooperación activa, la creación de una cultura de la paz que contribuya a un mejor aprovechamiento de los recursos y la constitución de ejes de acción mutuos en todos los ámbitos, desde la política hasta el deporte y la cultura. Chile y Perú no solo tienen una historia de desencuentros, 
sino también de cooperación, apoyo y hermandad. Ya que hemos hasta ahora propiciado lo primero, quizás sea hora de enfatizar lo segundo.

\section{Referencias}

Aljovín de Losada, C. (28 de agosto de 2010). Historiador de la Pontificia Universidad Católica del Perú. Comunicación personal. Lima, Perú.

Anderson, B. (1993). Comunidades imaginadas. Reflexiones sobre el origen y difusión del nacionalismo. Ciudad de México, México: Fondo de Cultura Económica.

Bonilla, H. (1980). Un siglo a la deriva. Lima, Perú: Instituto de Estudios Peruanos.

Cid, G. (2009). Un ícono funcional: la invención del roto como símbolo nacional, 1870-1888. En G. Cid y A. San Francisco (Eds.), Nación y nacionalismo en Chile. Siglo XIX. Vol. I. (pp. 221-254). Santiago, Chile: Ediciones Centro de Estudios Bicentenario.

Cavieres, E. (29 de abril de 2011). Académico en el Instituto de Historia de la Pontificia Universidad Católica de Valparaíso y en la Universidad de Chile, Premio Nacional de Historia 2008. Comunicación personal. Valparaíso, Chile.

Connor, W. (1998). Etnonacionalismo. Madrid, España: Trama editorial.

Cotler, J. (7 de septiembre de 2010). Sociólogo del Instituto de Estudios Peruanos. Comunicación personal. Lima, Perú.

Dager, J. (25 de agosto de 2010). Doctor en Historia de la Pontificia Universidad Católica de Chile y director del Archivo Histórico de Lima y del Archivo General de Lima. Comunicación personal. Lima, Perú.

De Althaus, M. (1979). Identidad nacional y Estado en el Perú. En A. de la Flor, M. De Althaus y A. Escobar (Eds.), Perú: identidad nacional (pp. 209-234). Lima, Perú: CEDEP.

De Gregori, C. (1978). Indigenismo, clases sociales y problema nacional: la discusión sobre el "problema indígena" en el Perú. Lima, Perú: Ediciones Centro Latinoamericano de Trabajo Social, CELATS. 
Florez, J. M. (2007). El viaje interior. La dinámica social peruana y el 'problema chileno'. En P. Milet y M. Artaza (Eds.), Nuestros vecinos (pp. 399-416). Santiago, Chile: RIL editores.

Foucault, M. (2002). Vigilar y castigar. Nacimiento de la prisión. Buenos Aires, Argentina: Siglo XXI editores.

González, S. (2008). La llave y el candado: el conflicto entre Perú y Chile por Tacna y Arica (1883-1929). Santiago, Chile: LOM ediciones / Universidad de Santiago de Chile.

Instituto de Opinión Pública, Pontificia Universidad Católica del Perú, Instituto de Investigación de Ciencias Sociales de la Universidad Diego Portales de Chile (2010). Perú y Chile: diferencias y coincidencias. Estado de la opinión pública V. Recuperado de http://e.peru21.pe/102/doc/0/0/2/4/1/241385.pdf

Jocelyn-Holt, A. (1997). El peso de la noche: nuestra frágil fortaleza histórica. Buenos Aires, Argentina: Espasa Calpe.

Larraín, J. (2001). Identidad chilena. Santiago, Chile: LOM ediciones.

. (18 de abril de 2011). Académico de la Universidad Alberto Hurtado. Comunicación personal. Santiago, Chile.

Mc Evoy, C. (1997). La utopía republicana: ideales y realidades en la formación de la cultura política peruana (1871-1919). Lima, Perú: Pontificia Universidad Católica del Perú / Fondo Editorial.

Quiroz Paz-Soldán, E. (1984). Cien años después. 1879-1979: reflexiones sobre la Guerra del Pacífico. Lima, Perú: Fundación M. J. Bustamante de la Fuente.

Robles Montoya, J. (2 de septiembre de 2010). Oficial de Ejército ${ }^{\circledR}$, máster en Administración de Empresas, analista de seguridad y defensa nacional. Comunicación personal. Lima, Perú.

Rodríguez, J. (2004). Chile-Perú: el siglo que vivimos en peligro. Santiago, Chile: La Tercera / Mondadori.

. (15 de junio de 2011). Periodista, abogado y exdiplomático. Comunicación personal. Santiago, Chile. 
Rodríguez, M. (2010). La soberanía marítima del Perú: la controversia entre el Perú y Chile. Lima, Perú: Derrama magisterial.

Subercaseaux, B. (1997). Historia de las ideas y de la cultura en Chile. Vol. 4. Santiago, Chile: Editorial Universitaria.

__—_. (2010). Raza y nación: ideas operantes y políticas públicas en Chile, 1990-1940. En G. Cid y A. San Francisco (Eds.), Nacionalismos e identidad nacional en Chile: siglo XX. Vol. II. (pp. 69-92). Santiago, Chile: Ediciones Centro de Estudios Bicentenario.

___—. (6 de mayo de 2011). Académico de la Universidad de Chile. Comunicación personal. Valparaíso, Chile.

Toche, E. (3 de septiembre de 2010). Historiador, investigador y analista político del Centro de Estudios y Promoción del Desarrollo del Perú. Comunicación personal. Lima, Perú.

Villalobos, S. (2002). Chile y Perú: la historia que nos une y nos separa, 1535-1883. Santiago, Chile: Editorial Universitaria. 